\title{
REAVALIAÇÃO TAXONÔMICA DOS GÊNEROS GANGAMOPTERIS E RUBIDGEA, PERMIANO INFERIOR DA BACIA DO PARANÁ, BRASIL
}

\author{
GRACIELA PEREIRA TYBUSCH \& ROBERTO IANNUZZI \\ Depto. de Paleontologia e Estratigrafia, UFRGS, Av. Bento Gonçalves, 9500, 91509-900, Porto Alegre, RS, Brasil. \\ gracielatybusch@yahoo.com.br; roberto.iannuzzi@ufrgs.br
}

\begin{abstract}
RESUMO - Os megafósseis vegetais aqui estudados são provenientes de diversos afloramentos do Permiano Inferior da bacia do Paraná, no Estado do Rio Grande do Sul, e compõe-se tanto de espécimes inéditos, como de material já descrito, atribuídos em parte ao gênero Rubidgea e, em parte, ao gênero Gangamopteris. O presente trabalho teve como objetivo a reavaliação taxonômica de espécimes preservados sob forma de impressões e incluídos em ambos os gêneros. Dezenove e 40 espécimes provenientes dos afloramentos Morro do Papaléo e Quitéria respectivamente, foram analisados, enquanto para os afloramentos Acampamento Velho, Faxinal, Pedreira e Cambaí Grande foram revisados dez espécimes. Foi constatado que todos os espécimes anteriormente atribuídos a Rubidgea pertencem a Gangamopteris, já que se enquadram na diagnose original deste último. Deste modo, conclui-se queo gênero Rubidgea não é reconhecido para o Permiano do Rio Grande do Sul. Além disso, três espécies já descritas e uma nova espécie de Gangamopteris foram registradas neste estudo: G. obovata, G. obovata var. major, G. buriadica e G. revoluta nov. sp. As amplitudes estratigráficas de todas as espécies são também fornecidas. Por último, as feições diagnósticas, em nível genérico, das folhas de glossopterídeas foram brevemente discutidas, dando-se especial ênfase às definições dos gêneros Gangamopteris e Rubidgea.
\end{abstract}

Palavras-chave: Gangamopteris, Rubidgea, bacia do Paraná, Permiano Inferior, Rio Grande do Sul, Brasil.

\begin{abstract}
TAXONOMIC REEVALUATION OF THE GENERA GANGAMOPTERIS AND RUBIDGEA, LOWER PERMIAN OF THE PARANÁ BASIN, BRAZIL. The plant megafossils studied herein have been recovered in several outcrops from the Lower Permian strata of the Paraná Basin in Rio Grande do Sul State, and represent both unpublished and described material. Based on these materials, this paper deals with the taxonomic revaluation of the Rubidgea and Gangamopteris genera. Nineteen and 40 specimens from the Morro do Papaléo and Quitéria outcrops were analyzed, respectively, and other 10 specimens from Acampamento Velho, Faxinal, Pedreira and Cambaí Grande outcrops were also studied. The revision confirms that all specimens previously included in Rubidgea could be transferred to genus Gangamopteris since they correspond to original diagnosis of this last genus. In conclusion, the genus Rubidgea is not assigned to the Permian deposits of state. Besides, three known species and a new species of genus Gangamopteris were assigned herein, as follow: G. obovata, G. obovata var. major, G. buriadica and G. revoluta nov. sp. The stratigraphic ranges of all species are also provided. Finally, the generic diagnostic features of glossopterid leaves were briefly discussed, giving a special emphasis to definition of genera Gangamopteris and Rubidgea.
\end{abstract}

Key words: Gangamopteris, Rubidgea, Paraná Basin, Lower Permian, Rio Grande do Sul State, southern Brazil.

\section{INTRODUÇÃO}

As folhas de glossopterídeas estão entre as plantas fósseis onde a classificação e nomenclatura se encontra menos elucidada, principalmente devido a sua peculiar venação secundária e à ausência, na maioria dos casos, de cutículas ou frutificações conectadas. Na Bacia do Paraná, destaca-se a presença de três morfogêneros de folhas de glossopterídeas, Rubidgea Tate, Gangamopteris McCoy e Glossopteris Brongn, compostos por várias espécies de ampla distribuição geográfica e/ou estratigráfica.

O gênero Rubidgea foi descrito, pela primeira vez no Brasil para o Grupo Itararé do Rio Grande do Sul, como Rubidgea sp., por Cazzulo-Klepzig et al. (1980). Posteriormente, sem descrever os espécimes, Rubidgea obovata Maithy e Rubidgea lanceolatus Maithy foram mencionadas e ilustradas para os afloramentos de Acampamento Velho, Morro do Papaléo, Fazenda Goulart e Faxinal, referentes a depósitos do topo do Grupo Itararé no Rio Grande do Sul (Cazzulo-Klepzig et al., 1980; Guerra-Sommer et al., 1980; Guerra-Sommer \& Cazzulo-Klepzig, 1981).

No trabalho de Millan \& Dolianiti (1982) foi proposta uma emenda à diagnose original de Tate (1867) ao gênero Rubidgea, com ênfase na adição de caracteres da morfologia foliar (forma do limbo, ápice, base e margens). Os autores descreveram ainda quatro espécies do gênero procedentes 
do Sítio Itapema, em Cerquilho, São Paulo, relativos aos depósitos do topo do Grupo Itararé, a saber: $R$. obovata e $R$. lanceolata, e duas espécies novas, $R$. lanceolata var. truncata e $R$. itapemensis.

Por fim, em Rohn et al. (2000) é noticiada uma tafoflora, de idade neocarbonífera a eopermiana, do Grupo Itararé, às margens do rio Capivari, em Tietê, São Paulo, composta predominantemente por: Rubidgea sp., Gangamopteris sp., Noeggerathiopsis?, Samaropsis sp., esfenófitas e algumas frutificações. No entanto, os autores não descrevem, mas apenas mencionam e ilustram com fotos, os espécimes referentes aos gêneros Rubidgea e Gangamopteris.

O primeiro conhecimento do gênero Gangamopteris no Brasil foi dado a saber através do trabalho de Carruthers (1869, apud Dolianiti, 1954b), onde o autor determinou como Noeggerathia obovata um espécime proveniente da região de Candiota, no Rio Grande do Sul, o qual foi considerado mais tarde por Zeiller (1895, apud Dolianiti, 1954b) como Euryphillum wittianum. Este espécime foi posteriormente reconhecido por Arber (1905) e Seward (1908) como idêntico a Gangamopteris cyclopteroides Feistmantel. No entanto, White (1908), ao estudar a flora fóssil associada aos carvões brasileiros, comentou de modo conclusivo que havia a prioridade do nome específico obovata sobre o epíteto cyclopteroides, da Índia. Lundquvist (1919, apud Dolianiti, 1954b) aceitou a proposição de White (1908) e considerou $G$. cyclopteroides Feistmantel como sinônimo júnior de $G$. obovata (Carr.) White.

Dolianiti (1954a) descreveu duas espécies do gênero Gangamopteris até então inéditas para o Gondwana brasileiro, a saber: Gangamopteris angustifolia McCoy e G. buriadica Feistmantel. Estas foram coletadas em afloramentos do topo do Grupo Itararé (= antiga Formação Maricá), na localidade de Acampamento Velho, Rio Grande do Sul, representando, na época, um significativo enriquecimento para o conhecimento da Flora Glossopteris brasileira. Já em Dolianiti (1954b), dando continuidade a uma série de pesquisas realizadas com vegetais fósseis da localidade de Bainha, município de Criciúma, Santa Catarina, o autor descreveu uma variedade já conhecida, Gangamopteris obovata var. major Feistmantel, e outra nova, Gangamopteris buriadica McCoy var. acrodeltoidis, além de uma espécie nova, Gangamopteris mosesi.

Posteriormente, no trabalho de Millan (1989) foram identificadas quatro espécies do gênero Gangamopteris na tafoflora do Sítio Itapema, em Cerquilho, São Paulo, para o topo do Grupo Itararé, a saber: Gangamopteris obovata, G. angustifolia McCoy, G. stephensonii Plumstead e uma espécie nova, G. dolianitii. Recentemente, Ricardi-Branco \& Bernardes de Oliveira (2000) fazem uma nova contribuição ao conhecimento do gênero na tafoflora do Sítio Itapema ao descrever uma espécie nova referente a um ramo foliar, Gangamopteris roesleri.

O principal objetivo desta contribuição é a reavaliação das formas de folhas de Glossopteridales ditas "gangamopteróides", ou seja, que não possuem o desenvolvimento de uma nítida venação mediana, encontradas no Permiano Inferior da Bacia do Paraná, no Rio Grande do Sul. Como o material estudado foi atribuído, em parte, ao gênero Rubidgea e, em parte, ao gênero Gangamopteris, também foi necessária uma reavaliação dos critérios morfológicos que os diagnosticam.

Foram revisados dez espécimes de formas anteriormente descritas (Cazzulo-Klepzig et al., 1980; Guerra-Sommer et al., 1980; Guerra-Sommer \& Cazzulo-Klepzig, 1981) identificados nos afloramentos Acampamento Velho, Faxinal, Pedreira, e Cambaí Grande. O contexto geológico destes afloramentos pode ser encontrado nos trabalhos de Cazzulo-Klepzig et al. (1980), Guerra-Sommer et al. (1980) e Guerra-Sommer \& Cazzulo-Klepzig (1993). Todos estes afloramentos foram considerados por aqueles autores como expondo níveis do Grupo Itararé, no Rio Grande do Sul, sem que, no entanto, tenham sido explicitados de modo mais preciso aqueles de onde provêm os espécimes. Os níveis fossilíferos foram apenas assinalados. Já os espécimes inéditos analisados provêm dos afloramentos Morro do Papaléo, e Quitéria, de níveis relativos tanto ao Grupo Itararé quanto à Formação Rio Bonito, no Rio Grande do Sul.

O afloramento Morro do Papaléo (coordenadas UTM N 6620; E 490) situa-se $8 \mathrm{~km}$ a noroeste do centro do município de Mariana Pimentel e cerca de $80 \mathrm{~km}$ de Porto Alegre. A descrição atualizada do afloramento encontra-se em Iannuzzi et al. (2003a, b; 2006). Foram coletados 18 espécimes na porção média da seção aflorante descrita, correspondente ao Nível 4 de Iannuzzi et al. (2003a, b) ou a Biofácies A de Vieira \& Iannuzzi (2000), os quais se encontram preservados em siltitos esbranquiçados interpretados como tendo sido gerados na margem de um corpo d'água lacustre/lagunar, correspondente a níveis do Grupo Itararé . Já na porção superior da seção, em níveis correspondentes aos Níveis 7 e 8 de Iannuzzi et al. (2003a, b) ou relativos à Biofácies D de Vieira \& Iannuzzi (2000), obtiveram-se 13 espécimes, ambos preservados em matriz siltíca-argilosa gerada em uma planície de inundação, dentro de um sistema fluvial do tipo anastomosado, correspondente a Formação Rio Bonito.

O afloramento de Quitéria é uma antiga pedreira localizada no município de Pantano Grande (UTM N 6643183; E 0387516), à cerca de $130 \mathrm{~km}$ de Porto Alegre. A descrição da seção aflorante foi feita por Piccoli et al. (1991), Jasper (2004) e Jasper et al. (2006). As amostras totalizaram 40 espécimes, provenientes da camada cinza-amarelada situada no topo da seção aflorante, e constituída de argilito, siltito e areia fina, em uma sucessão granocrescente. Este nível corresponde à Biofácies H de Picolli et al. (1991) e a fácies FS VI, horizontes c-d, de Jasper et al. (2006), correspondentes ao topo da Formação Rio Bonito na região e onde foram coletados caules de licófitas in situ.

\section{MATERIAL E MÉTODOS}

Todos os espécimes aqui referidos encontram-se preservados sob forma de impressões, sendo alguns compostos por partes e contra-partes. O estudo do material seguiu a metodologia padrão utilizada em Paleobotânica para 
análise de impressões/compressões, como segue: observação em lupa binocular, medições a partir de paquímetro e régua, ilustrações elaboradas com auxílio de material fotográfico e câmara clara. Para realizar a descrição e comparação dos espécimes, características morfográficas, tais como forma do limbo e tipos de ápice e de base foliar, foram definidas de acordo com a classificação adotada por Chandra \& Surange (1979). Para obtenção das características referentes à densidade de venação, aos ângulos de emergência e divergência da venação secundária e à largura máxima da venação mediana, foram utilizados os parâmetros e as técnicas descritas por Rohn et al. (1984). Com a finalidade de sistematizar, ou mesmo estimar, o tamanho foliar aproximado dos espécimes, mesmo aqueles relativamente incompletos, foi empregada a classificação relativa às dimensões dos megáfilos, proposta por Ash et al. (1999).

Com o objetivo de tornar clara a descrição dos tipos de anastomoses presentes na venação da lâmina foliar dos espécimes estudados, estipularam-se três categorias assim definidas: a) conexões obliquas: originadas a partir da bifurcação, em ângulos agudos, de veias secundárias vizinhas que seguem paralelamente em direção à margem; b) conexões transversais: originadas de veias transversais (subparalelas às veias medianas, ou feixe central, ou em ângulos quase retos) que conectam veias secundárias vizinhas que seguem paralelamente em direção à margem foliar; c) conexões em X: originadas do encontro ou cruzamento de veias secundárias vizinhas, que seguem paralelamente em direção à margem foliar (Figura 1).

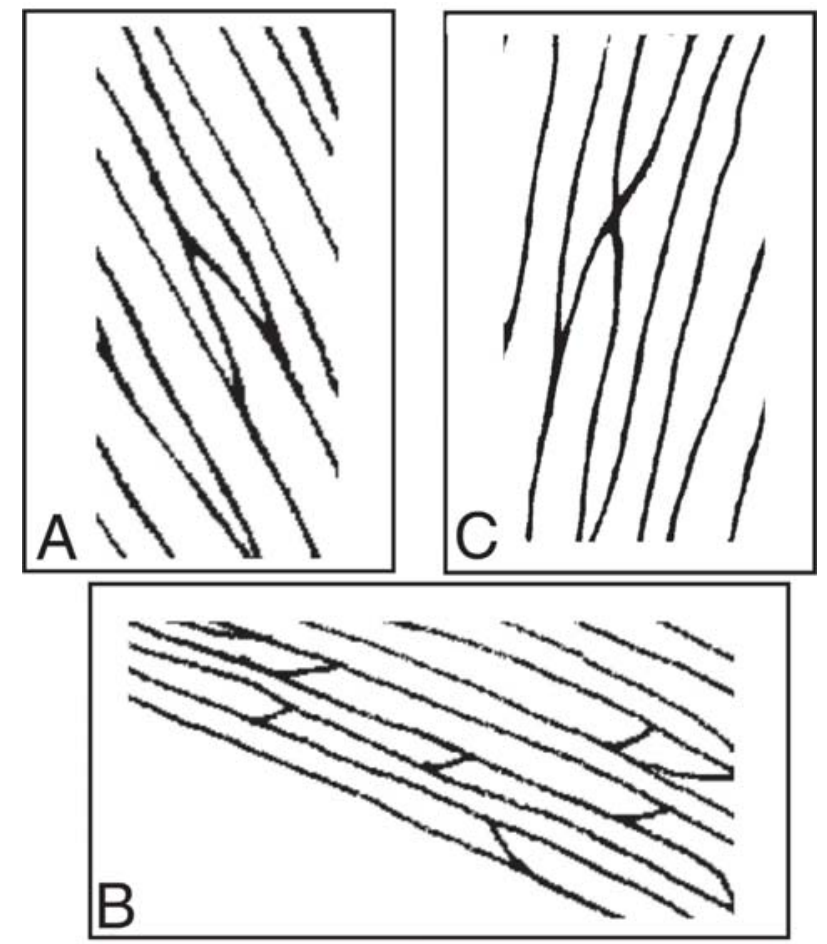

Figura 1. Tipos de anastomoses em folhas de glossopterídeas: A, conexão oblíqua; B, conexão transversal; C, conexão em " $X$ ".

Figure 1. Distinct types of anastomoses present in glossopterid leaves: A, oblique connection; B, transversal or cross-connection; C, X-type connection.
O material paleobotânico analisado encontra-se depositado no Museu de Paleontologia (MP), do Departamento de Paleontologia e Estratigrafia (DPE), do Instituto de Geociências (IG), da Universidade Federal do Rio Grande do Sul (UFRGS), tendo sido catalogados sob a sigla $\mathrm{MP}-\mathrm{Pb}$. A sistemática supra-genérica segue a estabelecida por Stewart \& Rothwell (1993).

\section{SISTEMÁTICA PALEONTOLÓGICA}

\section{Morfogênero Rubidgea}

O nome genérico Rubidgea foi primeiramente instituído por Tate (1867) para dois espécimes provenientes da África do Sul, denominados de $R$. mackayi. Estes apresentavam como principais características diagnósticas a presença de uma venação dicotômica, desprovida de anastomoses e nervura mediana proeminente. Desde então, nenhuma outra ocorrência do gênero foi assinalada no Gondwana até que Maithy (1965a) noticiou sua presença nas formações carboníferas de Giridih, em Bihar, Índia, descrevendo duas novas espécies: $R$. obovata e $R$. lanceolatus.

Arber (1905), em face da ausência de uma fotografia do espécime original de Tate (1867), posicionou o gênero como uma forma "incertae sedis". Seward (1907) sinonimizou $R$. mackayi em Glossopteris indica, considerando o desenho de Tate (1867) inexato e acreditando que, aparentemente, o espécime original tenha se extraviado, uma vez que desde que o gênero foi descrito ele nunca mais fora visto. KovácsEndrödy (1977), por sua vez, confirmou a suposição de Seward (1907) após realizar um estudo em larga escala de impressões foliares encontradas em uma pedreira próxima ao Hammanskraal, na África do Sul. Analisando uma folha praticamente inteira, com impressões nítidas das superfícies superior e inferior preservadas (parte e contra-parte), a autora percebeu que as impressões em ambas superfícies eram diferentes, a adaxial típica de Rubidgea (= folha sem anastomoses) enquanto que a abaxial era típica de Glossopteris (= folha com anastomoses e venação mediana proeminente), sendo, em alguns casos possível de ser observado na mesma impressão foliar, os dois tipos de superfícies. Segundo ela, isto ocorria porque a maioria das plantas mostra impressões da superfície superior sem traços marcantes e nervuras salientes. Quanto à ausência de uma venação mediana, Kovács-Endrödy (1977) acredita que haja uma dificuldade inerente à interpretação do que representaria, na verdade, uma "venação mediana" nas folhas das glossopterídeas. Este fato, juntamente com o de que as diferenças entre as superfícies superior e inferior das folhas de glossopterídeas são usualmente ignoradas nos demais estudos, levou Kovács-Endrödy (1977) a sinonimizar a espécie tipo de Rubidgea no gênero Glossopteris, designando-a como Glossopteris mackai (Tate) Kovács comb. nov.

Apesar dos autores crêem que situações como a descrita por Kovács-Endrödy (1977), onde há distorções tafonômicas, serem plenamente plausíveis, no presente trabalho se aceita a posição de Maithy (1965) na qual se considera Rubidgea 
como um morfogênero ainda válido, uma vez que a refutação do mesmo dependeria de um exame mais acurado dos espécimes indianos. Além disso, restaria também a análise dos espécimes provenientes do Grupo Itararé, em São Paulo, classificados em Rubidgea por Millan \& Dolianiti (1982).

\section{Morfogênero Gangamopteris}

O gênero Gangamopteris foi originalmente descrito por McCoy (1847), primeiramente como Cyclopteris angustifolia, uma folha mostrando um padrão de venação típica de Glossopteris, mas sem venação mediana nítida. Posteriormente, após McCoy (1860, apud Maithy, 1966) ter examinado um grande número de espécimes coletados no Bacchus-Marsh Sandstone, em Victoria, Austrália, chegou à conclusão de que as anastomoses das veias e a ausência de venação mediana eram características constantes nestas folhas de glossopterídeas e, por esta razão, ele propôs o novo nome genérico Gangamopteris para este tipo foliar. Na presente contribuição, considera-se válido o morfogêneoro Gangamopteris, assim como definido por McCoy.

\section{Rubidgea versus Gangamopteris}

A classificação das folhas de glossopterídeas, especialmente quando se tratam apenas de impressões, é cercada de uma série de aspectos que dificultam sua precisa inserção taxonômica. Diversos autores já expressaram dúvidas sobre a viabilidade de sua classificação quando frutificações ou cutículas estão ausentes (Arber, 1902; Arber, 1905; Seward, 1907; Seward, 1910; Walkom, 1922; Surange \& Srivastava, 1956; Maithy, 1966; Kovács-Endrödy, 1977; Chandra \& Surange, 1979). Quando se têm apenas impressões de folhas, a identificação de cada morfogênero é baseada nas características do padrão de venação (presença/ausência de venação mediana e tipo de venação secundária); forma e tamanho são feições que têm sido relevantes apenas quando as morfoespécies apresentam um padrão de venação muito semelhante entre si.

Srivastava (1991), no seu trabalho sobre tendência evolucionária da venação secundária das glossopterídeas, separa os gêneros em duas categorias baseado na ausência (morfogêneros Euryphyllum, Rubidgea, Palaeovittaria e Rhadotaenia) ou presença (Gangamopteris, Glossopteris e Belemnopteris) de malhas de veias. Dentro de cada categoria existe uma variação de formas sem venação mediana, formas intermediárias e formas com venação mediana proeminente.

Millan \& Dolianiti (1982), para distinguir Rubidgea dos demais gêneros de glossopterídeas, também se basearam nas características do padrão de venação e enfocaram o formato foliar e tamanho apenas para determinar as diferentes espécies de Rubidgea. Já Maithy (1998) apresentou exemplos de como a natureza da venação é a característica mais importante na identificação dos morfogêneros nas folhas de glossopterídeas.

Levando-se em consideração o exposto acima, os espécimes aqui estudados são classificados com base nas características do padrão de venação. Deste modo, Gangamopteris é um tipo foliar caracterizado pela ausência de uma venação mediana (apresenta, no máximo, um sulco mediano e/ou um feixe de veias subparalelas na porção central) e pela presença de um padrão de venação formando malhas ou anastomoses ao longo da lâmina. Por sua vez, a ausência destes aspectos anatômicos caracterizaria o morfogênero Rubidgea.

\section{Divisão TRACHEOPHYTA \\ Classe GYMNOSPERMOPSIDA \\ Ordem GLOSSOPTERIDALES \\ Gangamopteris McCoy 1847}

Espécie-tipo. Cyclopteris angustifolia McCoy, 1847 (G. angustifolia McCoy, 1875)

Gangamopteris revoluta nov. sp.

(Figuras 2, 3)

Gangamopteris angustifolia (auct. non) McCoy 1875. Côrrea da Silva \& Arrondo, 1977:40, est.1, fig.4.

Gangamopteris angustifolia (auct. non) McCoy 1875. Cazzulo-Klepzig et al., 1980:59, est.1, fig.8.

Rubidgea sp. Cazzulo-Klepzig et al., 1980:59, est.2, fig.1.

Rubidgea sp. Cazzulo-Klepzig et al., 1980:67, est.3, fig. 5.

Gangamopteris angustifolia (auct. non) McCoy 1875. Cazzulo-Klepzig et al.,1980:6, est.3,fig.14.

Rubidgea sp. Guerra-Sommer \& Cazzulo-Klepzig, 1981:137, est.2, fig.6.

Rubidgea lanceolatus (auct. non) Maithy 1965a. GuerraSommer \& Cazzulo-Klepzig,1993:65, pl.1, fig.4.

Holótipo. MP-Pb 3736.

Parátipos. Afloramento Morro do Papaléo: MP-Pb 2389, 2390 A, 2390 B, 3458, 4410, 4411; Afloramento Acampamento Velho: MP-Pb 2276; Afloramento Cambaí Grande: MP- Pb 3099.

Localidade-tipo. Afloramento Morro do Papaléo, Mariana Pimentel, RS.

Ocorrência. Níveis fossilíferos $4(=\mathrm{N} 4)$, no topo do Grupo Itararé, e 8 (=N8), na Formação Rio Bonito, conforme Iannuzzi et al. $(2003 \mathrm{a}, \mathrm{b})$.

Idade. Permiano (Sakmariano tardio - Artinskiano precoce). Etimologia. Em alusão ao fato do limbo ser acentuadamente enrolado sobre si mesmo, em direção a sua provável superfície inferior, uma das principais características diagnósticas da espécie.

Etymology. Name referring to a strongly curled lamina towards its possible lower surface; it is one of the main diagnostic features of this species.

Diagnose. Folhas simples, de margens inteiras, simétricas, pequenas, de limbo enrolado e forma lanceolada a estreitamente oblonga; ápice agudo e base ausente. Região mediana ocupada por veias subparalelas e por um estreito sulco que se estende ao longo da lâmina. Veias laterais curvando-se ligeiramente para os bordos foliares, em ângulos de $12^{\circ}$ a $25^{\circ}$, nas regiões mais inferiores e próximas às margens foliares, e $5^{\circ}$ a $10^{\circ}$, nas regiões mais superiores e próximas à região mediana; as veias bifurcam-se várias vezes, principalmente próximo aos bordos. As anastomoses, em geral raras, são formadas por conexões do tipo oblíquas, 

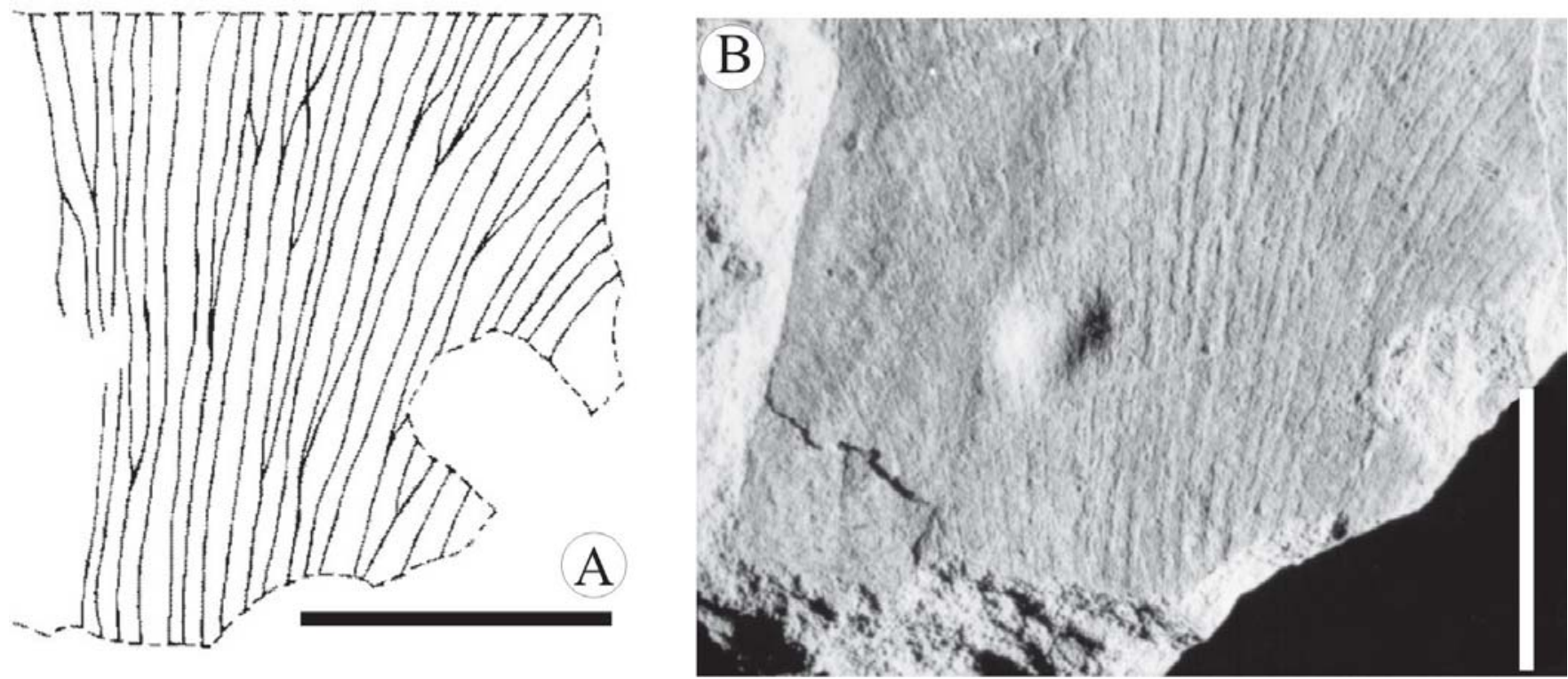

Figura 2. Gangamopteris revoluta nov. sp, espécime MP-Pb 2276: A, desenho mostrando venação; B, foto mostrando em detalhe o padrão da venação. Escalas $=1 \mathrm{~cm}$.

Figure 2. Gangamopteris revoluta nov. sp, specimen MP-Pb 2276: A, drawing showing the venation pattern; B, photo showing a detail of the venation pattern. Scale bars $=1 \mathrm{~cm}$.

transversais e raramente em forma de "X", dando origem a retículos alongados e poligonais, sendo mais freqüentes nas áreas próximas às margens das folhas.

Diagnosis. Simple small leaves with entire and symmetric margins, lanceolate- to narrowly oblong shapes and strongly curled lamina, tapering to elongate acute apex; base unknown. The median leaf regions show subparallel veins and a narrow furrow extending from the basal region up to apices. Lateral veins curving slightly towards leaf margins, at angles of $12^{\circ}$ to $25^{\circ}$, in the basal region near lateral leaf margins, and at angles of $5^{\circ}$ to $10^{\circ}$, in the apical region near to median leaf area; veins forking several times, mostly near margins. The anastomoses are generally rare and arise from oblique-, transversal- or X-type vein connections, giving rise to elongate and polygonal mashes; they occur in highest frequency near to leaf margins.

Descrição. Folhas simples, de margens inteiras, simétricas, todas notófilas, com apenas um ápice preservado e bases foliares sempre ausentes, encontrando-se, em sua maioria, apenas a região mediana preservada. O limbo é acentuadamente enrolado sobre si e de forma lanceolada nos espécimes MP-Pb 2276 e 3736 e estreitamente oblonga nos demais espécimes; o ápice é agudo (MP-Pb 2276). No comprimento das folhas o menor valor medido foi de $8,4 \mathrm{~cm}$ (MP-Pb 2389) e o maior de 14,7 cm (MP-Pb 3736); a largura foliar apresenta o menor valor medido de 2,2 cm (MP-Pb 3099) e o maior de 3,8 cm (MP-Pb 3736). A região mediana é ocupada por veias subparalelas e um estreito sulco que se estende ao longo de toda a lâmina. As veias laterais curvam-se para os bordos foliares em ângulos de $12^{\circ}$ (MP-Pb 2390) a $25^{\circ}$ (MP$\mathrm{Pb} 3736)$ nas regiões mais inferiores e próximas as margens foliares, e de $5^{\circ}$ (MP-Pb 2390, 3099) a $10^{\circ}$ (MP-Pb 3736), nas regiões mais apicais e próximas à região mediana; as veias bifurcam-se várias vezes, principalmente próximo aos bordos foliares, onde também ocorrem com maior freqüência as anastomoses que são formadas por conexões obliquas, transversais e, mais raramente, em " $X$ ", embora as anastomoses ocorram, como um todo, em pouca quantidade ao longo das folhas. Os retículos têm formatos alongados a poligonais (Figura 2A, B).

Observações. $\mathrm{O}$ formato descrito para o limbo é apenas sugestivo pelo fato das folhas encontrarem-se enroladas sobre si mesmas, o que impede uma observação da real forma do mesmo. O enrolamento do limbo pode ser comprovado ao se analisar os espécimes MP-Pb 2389 e MP-Pb 3099 que apresentam a continuidade das porções laterais dos limbos aparecendo por baixo das porções mais centrais, que foram previamente removidas. Nestas porções laterais subjacentes se observa, por conseguinte, que as nervuras correm nitidamente no sentido inverso às das partes sobrejacentes do limbo foliar (Figura 3D, E).

Discussão. A re-análise dos espécimes classificados como Rubidgea nos trabalhos de Cazzulo-Klepzig et al. (1980), Guerra-Sommer \& Cazzulo-Klepzig (1981) e Guerra-Sommer \& Cazzulo-Klepzig (1993), mostrou que os mesmos apresentavam anastomoses entre as veias ao longo do limbo foliar, formando malhas. Logo, optou-se aqui por classificálos dentro do gênero Gangamopteris, uma vez que este suporta a presença de retículos, como já discutido acima, no subitem "Gangamopteris versus Rubidgea".

Em nível específico, o material estudado assemelha-se, quanto ao formato do limbo, com as espécies Gangamopteris mosesi Dolianiti (Archangelsky, 1957) e G. angustifolia McCoy (Feistmantel, 1879; Dolianiti, 1954a; Archangelsky, 1957; Plumstead, 1962; Rigby \& Chandra, 1990). Contudo, a forma aqui descrita difere de G. mosesi por apresentar a região 

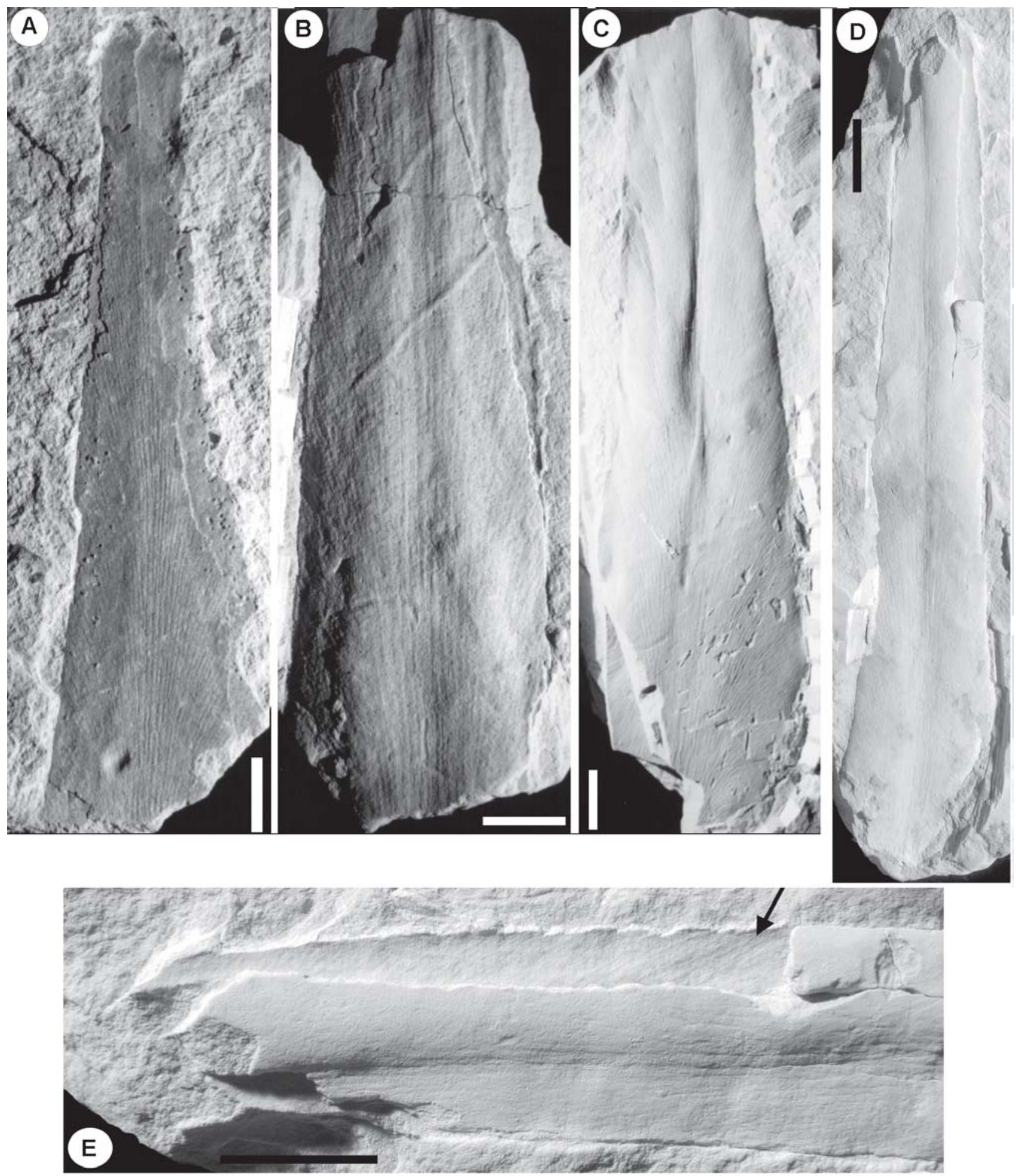

Figura 3. Gangamopteris revoluta nov. sp.: A, parátipo MP-Pb 2276, folha lanceolada e limbo enrolado com ápice agudo; B, parátipo MP$\mathrm{Pb} 2389$, folha estreitamente oblonga e limbo enrolado, com sulco na região mediana; $\mathbf{C}$, holótipo MP-Pb 3736 , folha lanceolada de limbo enrolado, com estreito sulco na região mediana e veias laterais curvando-se acentuadamente em direção às margens nas regiões inferiores; D, E, parátipo MP-Pb 3099 (D) folha de limbo enrolado e forma estreitamente oblonga, com sulco mediano, (E) detalhe da folha apresentando a continuidade da porção marginal do limbo que parece por de trás de uma porção removida do mesmo, com as veias correndo no sentido inverso às da porção superior do limbo foliar (seta). Escalas $=1 \mathrm{~cm}$

Figure 3. Gangamopteris revoluta nov. sp.: A, paratype MP-Pb 2276, lanceolate leaf with enrolled lamina and acute apex; B, paratype MP$\mathrm{Pb} 2389$, narrow oblong leaf with enrolled lamina and a narrow furrow in the median leaf region; C, holotype MP-Pb 3736, lanceolate leaf with enrolled lamina and a narrow furrow in the median leaf region and lateral veins clearly curving towards margins in the basal region; D, E, paratype MP-Pb 3099 (D) narrow oblong leaf with enrolled lamina and narrow furrow in the median leaf region, (E) detail of leaf, showing the continuity of marginal lamina running below the partial recovered upper surface of leaf, where the veins run in opposite direction of those at the upper surface (arrow). Scale bars $=1 \mathrm{~cm}$. 
mediana ocupada por veias subparalelas e um estreito sulco que se estende ao longo da lâmina. Ela também se distingue de G. angustifolia pela folha simétrica e presença de sulco mediano. O material estudado ainda se compara à $G$. stephensoni Plumstead (Plumstead, 1962) por apresentar região mediana ocupada por um estreito sulco e, também, por sua folha simétrica. Entretanto, difere completamente no formato da folha, que varia de lanceolado a estreitamente oblongo, enquanto que na espécie indiana o limbo é redondo a oval. Além disso, nenhuma das espécies próximas, citadas acima, apresentou o limbo fortemente recurvado sobre si, característica diagnóstica marcante da forma aqui estudada.

\section{Gangamopteris buriadica Feistmantel 1879}

(Figuras 4, 5)

Material estudado. Afloramento Morro do Papaléo: MP-Pb 889, 3998, 3999, 4000, 4001, 4002; Afloramento de Quitéria: MP-Pb 2355, 2356A, 2356C, 2891, 3060A, 3060B, 3213, 3275, 4003, 4004, 4005, 4006, 4007ab, 4008ab, 4009ab, 4010, 4011, 4012, 4013A, 4013B, 4015aA, 4015b, 4016ab, 4017, 4018, 4019, 4021, 4022, 4023ab, 4024, 4025, 4026, 4027, 4028, 4029, 4040ab, 4041ab, 4042, 4043, 4044; Afloramento Acampamento Velho: MP-Pb 3157.

Material descrito. Afloramento Morro do Papaléo: $\mathrm{MP}-\mathrm{Pb}$ 889, 3998, 4000, 4001, 4002; Afloramento de Quitéria: MP-Pb 2356A, 2356C, 2891, 3060B, 3275, 4003, 4004, 4007ab, 4008ab, 4009ab, 4012, 4013A, 4014ab, 4015aA, 4018, 4019, 4022, 4023ab, 4040ab, 4041 ab; Afloramento Acampamento Velho: MP-Pb 3157.

Ocorrência. Nível fossilífero 4 (= N4), no topo do Grupo Itararé, conforme Iannuzzi et al. (2003a, b); Fácies FS VI, horizontes c-d, no topo da Formação Rio Bonito, segundo Jasper et al. (2006).

Idade. Permiano (Sakmariano tardio - Artinskiano precoce).

Descrição. O material analisado é constituído por folhas simples, de margens inteiras, simétricas, variando de micrófilas a mesófilas, a maioria apenas com a porção mediana preservada, sendo que três espécimes apresentam o ápice (MP-Pb 889, 3157, 4008ab) e alguns a porção basal. O formato do limbo varia de estreitamente oblongo (MP-Pb 3060B, 4004, 4007ab, 4022, 4023ab, 4040ab) a estreitamente oblanceolado (MP-Pb 4041ab); os ápices variam de obtuso (MP-Pb 889), truncado arredondado (MP-Pb 3157) a agudo (MP-Pb $4008 \mathrm{ab}$ ); a porção basal é estreita e vai afilando-se aos poucos (MP-Pb 4003, 4041ab), sendo que, no espécime MP-Pb 4041ab, esta porção apresenta-se, aparentemente, enrolada sobre si mesma; o comprimento das folhas varia de mais de 4,2 cm (MP-Pb 4001) a maior que 18,5 cm (MP-Pb 4004); a largura foliar apresenta desde valores superiores a 2,4 cm (MP-Pb 3998 ) até maiores que 4,6 cm (MP-Pb 4022). A região mediana é ocupada por veias paralelas e subparalelas que se iniciam na porção basal e seguem até o ápice da folha. As veias laterais são quase eretas, curvando-se levemente em direção às margens foliares em ângulos de $6^{\circ}(\mathrm{MP}-\mathrm{Pb} 4004,4007 \mathrm{ab}$, $3157)$ a $10^{\circ}$ (MP-Pb 4007ab, 4009ab), possuindo uma curvatura um pouco mais acentuada que varia de $12,5^{\circ}(\mathrm{MP}-\mathrm{Pb} 2276)$ a $16^{\circ}$ (MP-Pb 3157), nas porções mais inferiores do limbo. As veias bifurcam-se várias vezes, encontrando-se raras anastomoses ao longo de toda lâmina foliar, formadas a partir de conexões do tipo obliquas, transversais e em " $X$ ", que dão origem a retículos muito alongados e poligonais (Figura 4).

Discussão. Como os espécimes analisados apresentam anastomoses entre as veias, mesmo que por vezes raras, formando malhas ou retículos, e não apresentam uma nítida venação mediana, opta-se por classificá-los dentro do gênero Gangamopteris que abarca tais características.

O material estudado compara-se a Gangamopteris buriadica Feistmantel (Feistmantel, 1879; Dolianiti, 1954a), G. buriadica var. acrodeltoides Dolianiti (Dolianiti, 1954b) e G. mosesi Dolianiti (Dolianiti, 1954b), quanto à região mediana, por ser ocupada por veias paralelas e subparalelas que iniciamse na porção basal e seguem até o ápice da folha, e por apresentar veias laterais praticamente eretas. Contudo, difere de G. buriadica var. acrodeltoides e G. mosesi, pela forma do limbo oblanceolada a estreitamente oblonga e por seu ápice que varia de agudo, obtuso a truncado arredondado. Distingue-se ainda de G. buriadica var. acrodeltoides por apresentar folhas simétricas. Entretanto, demonstra estreita semelhança com $G$. buriadica devido à presença de ápice truncado arredondado, de uma porção basal estreita que vai se afilando aos poucos, de uma região mediana ocupada por veias paralelas e subparalelas e veias laterais quase eretas que se curvam ligeiramente em direção às margens foliares, de modo um pouco mais acentuado nas porções mais inferiores do limbo. Deste modo, inclui-se o material estudado na espécie $G$. buriadica, com a qual apresenta uma nítida identidade em nível específico.

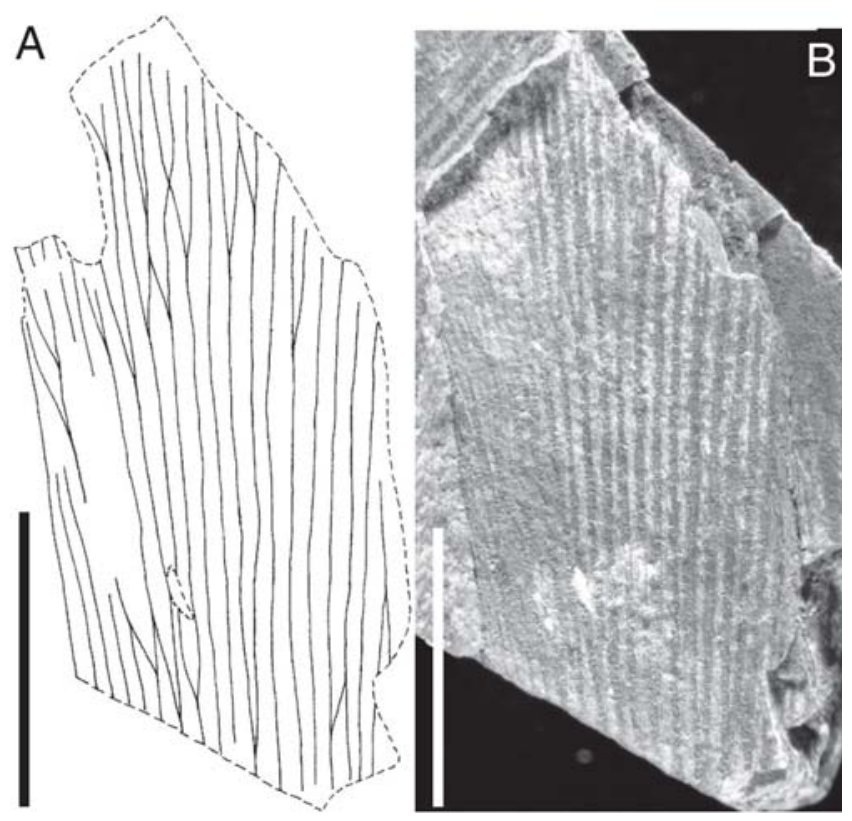

Figura 4. Gangamopteris buriadica Feistmantel, espécime MP-Pb 4015b: A, desenho da venação; B, foto com detalhe do padrão da venação. Escalas $=1 \mathrm{~cm}$

Figure 4. Gangamopteris buriadica Feistmantel, specimen MP-Pb 4015b: A, drawing of the venation pattern; B, photo with detail of the venation pattern. Scale bars $=1 \mathrm{~cm}$ 

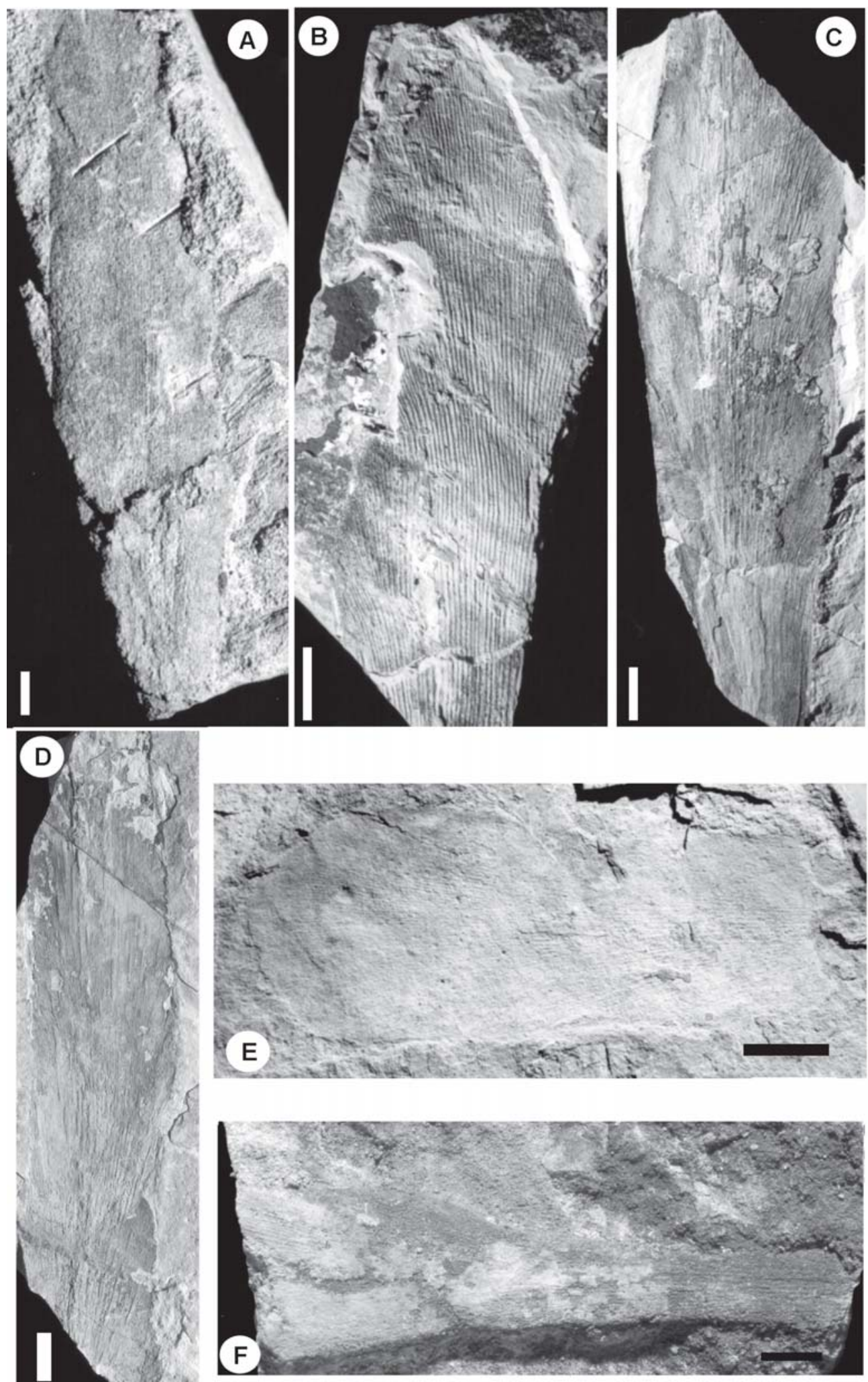

Figura 5. Gangamopteris buriadica Feistmantel: A, MP-Pb 4004, folha com apenas a região mediana preservada, com limbo estreitamente oblongo e veias laterais praticamente eretas; $\mathrm{B}, \mathrm{MP}-\mathrm{Pb} 4008 \mathrm{a}$, folha com ápice agudo e veias laterais praticamente eretas; C, MP-Pb 4007a, e D, MP-Pb 4040a, folhas com apenas a região mediana preservada, mostrando formatos dos limbos estreitamente oblongos e as veias laterais praticamente eretas; E, MP-Pb 3157, folha de ápice truncado arredondado; F, MP-Pb 4041a, porção basal da folha estreita que aos poucos vai afilando-se, mostrando-se aparentemente enrolada. Escalas $=1 \mathrm{~cm}$.

Figure 5. Gangamopteris buriadica Feistmantel: A, MP-Pb 4004, median region of leaf with narrow oblong-shaped leaf and lateral veins quite erects; B, MP-Pb 4008a, leaf with acute apex and lateral veins quite erects C, MP-Pb 4007a, and D, MP-Pb 4040a, median regions showing narrow oblong-shaped leaves and lateral veins quite erects; E, MP-Pb 3157, leaf with rounded truncate apex; F, MP-Pb 4041a, basal region of narrow leaf ending slightly towards base, showing the enrolled lamina apparently. Scale bars $=1 \mathrm{~cm}$. 
Cabe salientar que G. buriadica é um táxon considerado de classificação duvidosa por alguns autores, tais como, Arber (1905) e Maithy (1998). O último propõe a inclusão desta espécie no gênero Karharbariphyllum, uma forma semelhante a Noeggerathiopsis, porém com a presença de conexões entre as veias formando malhas semelhantes a Gangamopteris. Deste modo, Maithy (1998) erigiu Karharbariphyllum para designar folhas que possuem, segundo ele, características de ambos os gêneros, Noeggerathiopsis e Gangamopteris, como no caso de G. buriadica. Neste trabalho, optou-se por continuar incluindo esta última espécie dentro do gênero Gangamopteris. A presença de veias subparalelas, eretas e que se dicotomizam não parece ser para os autores uma característica suficientemente diagnóstica para se propor um novo gênero, como proposto por Maithy (1998).

\section{Gangamopteris obovata (Carr.) White 1908}

(Figuras 6,7B-F)

Gangamopteris sp. Cazzulo-Klepzig et al., 1980:65, est.2, fig.3 . Rubidgea sp. Guerra-Sommer et al., 1980,est.1, fig.8.

Rubidgea sp. Guerra-Sommer \& Cazzulo-Klepzig, 1980:137,est.2, fig.5.

Rubidgea obovata (auct. non) Maithy 1965a. Guerra-Sommer \& Klippel, 1980:608,610, est.2, fig.2, fig. 1d.

Rubidgea obovata (auct. non) Maithy 1965a. Guerra-Sommer \& Cazzulo-Klepzig, 1993:65, pl.1, fig.1.

Rubidgea sp. Guerra-Sommer \& Cazzulo-Klepzig, 2000a:487, fig.2a,c.

Rubidgea obovata (auct. non) Maithy 1965a. Guerra-Sommer \& Cazzulo-Klepzig, 2000b:69, fig.1e.

Material descrito. Afloramentos Morro do Papaléo: MP-Pb 2002, 2581,3460A, 3460B, 3462, 3463, 3573ab, 3647, 4408, 4409; Acampamento Velho: MP-Pb 2281, 2287, 3155; Faxinal: MP$\mathrm{Pb}$ 2318, 2319; Pedreira: MP-Pb 2248, 2249.

Ocorrência. Níveis fossilíferos 4 (= N4), no topo do Grupo Itararé, e 8 (=N8), na Formação Rio Bonito, conforme Iannuzzi et al. $(2003 \mathrm{a}, \mathrm{b})$.

Idade. Permiano (Sakmariano tardio - Artinskiano precoce). Descrição. O material estudado representa folhas simples, de margens inteiras e suavemente onduladas na porção apical, simétricas, em geral com ápices foliares preservados e bases ausentes, de dimensões variando de nanófila a notófila. A forma do limbo é oblanceolada; o ápice é obtuso a levemente redondo (presente apenas no espécime MP-Pb 3573ab); o limbo vai estreitando-se em direção a região basal, o que sugere bases agudas a truncadas; o comprimento das folhas varia de mais de 2,5 cm (MP- $\mathrm{Pb} 2318$ ) a maior que 6,8 cm (MP$\mathrm{Pb} 3573 \mathrm{ab})$; a largura foliar apresenta desde valores superiores a 1,4 cm (MP-Pb 2318, 3460A) até maiores que 3,8 cm (MP-Pb $3573 \mathrm{ab}$ ). A região mediana é ocupada por veias subparalelas que se iniciam na porção basal, onde anastomoses são muito raras, e seguem até o ápice da folha, onde se apresentam mais difusas (Figura 6A, B). Entretanto, os espécimes apresentam certa variação quanto à venação central, alguns possuem feixes centrais mais nítidos e proeminentes (MP-Pb

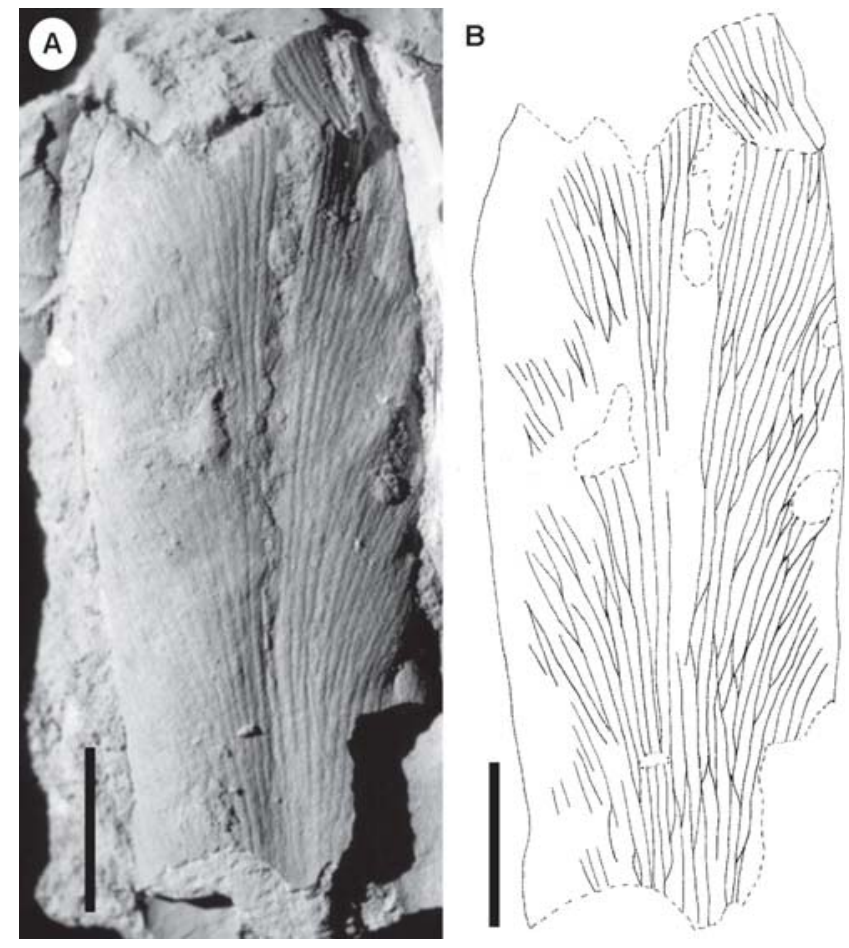

Figura 6. Gangamopteris obovata (Carr.) White, MP-Pb 2002: foto (A) e desenho (B) mostrando o padrão da venação. Escalas $=1 \mathrm{~cm}$. Figure 6. Gangamopteris obovata (Carr.) White, MP-Pb 2002: photo $(\mathbf{A})$ and drawing $(\mathbf{B})$ showing the venation pattern. Scale bars $=1 \mathrm{~cm}$.

2002, 2581,3460A), outros apresentam uma venação central mais frouxa (MP-Pb 2249, 2287, 3573ab), e existem ainda aqueles que são intermediários a estas duas variações (MP$\mathrm{Pb} 3463,3647)$. As veias laterais bifurcam-se várias vezes, curvando-se muito suavemente para os bordos na porção basal da folha, onde apresentam um ângulo de curvatura que varia de $7^{\circ}(\mathrm{MP}-\mathrm{Pb} 3460 \mathrm{~A}, 3647)$ a $10^{\circ}(\mathrm{MP}-\mathrm{Pb} 3155)$, e mais acentuadamente nas porções mediana e apical da folha, onde a variação do ângulo é de $13^{\circ}$ (MP-Pb 2002, 3573ab) a $18^{\circ}$ (MP-Pb 2002, 3463). As anastomoses formam-se a partir de conexões obliquas e, mais raramente, através de conexões em forma de $X$, ocorrendo com maior freqüência especialmente próximo aos bordos da folha, onde as nervuras encontramse mais próximas. Embora em pouca quantidade, as anastomoses formam retículos poligonais e muito alongados (Figura 6).

Discussão. Ao se analisar os melhores espécimes classificados como Rubidgea por Cazzulo-Klepzig et al. (1980), Guerra-Sommer et al. (1980), Guerra-Sommer \& Cazzulo-Klepzig (1981), Guerra-Sommer \& Klippel (1985), Guerra-Sommer \& Cazzulo-Klepzig (1993), Guerra-Sommer \& Cazzulo-Klepzig (2000a) e Guerra-Sommer \& Cazzulo-Klepzig (2000b), verificou-se que todos apresentavam anastomoses entre as veias, formando malhas, embora em alguns casos elas fossem raras. Deste modo, optou-se aqui por classificar esses espécimes em Gangamopteris, uma vez que este gênero suporta a presença de retículos constatada nos mesmos, como já discutido anteriormente (Gangamopteris versus Rubidgea). 

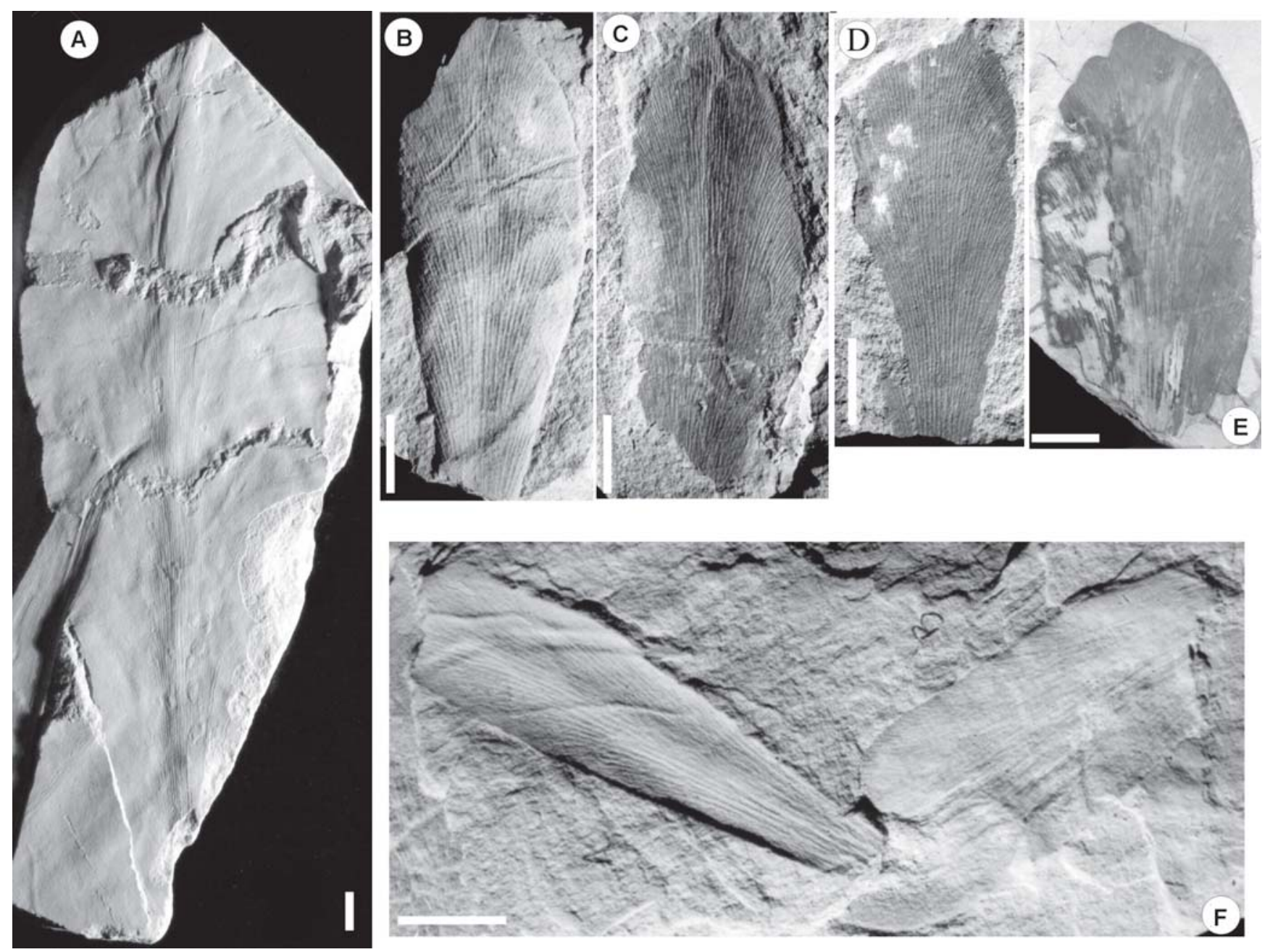

Figura 7. Gangamopteris obovata var. major (Feistmantel) Dolianiti: A, MP-Pb 3704, folha oblanceolada-espatulada, com região mediana ocupada por feixes centrais mais proeminentes na porção basal que se esvaecem em direção ao ápice. G. obovata (Carr.) White: B, MP$\mathrm{Pb} 3647$, folha mostrando com limbo oblanceolado, ápice obtuso, porção basal gradativamente estreito, região mediana ocupada por feixes centrais pouco nítidos e proeminentes, e veias laterais que se curvam mais acentuadamente nas porções mediana e apical da folha; C, MP-Pb 2581, limbo oblanceolado com suaves ondulações nas margens da porção apical, feixes centrais nítidos e proeminentes na região mediana; D, MP-Pb 2287, folha de margens suavemente onduladas na porção apical, com limbo oblanceolado, venação central frouxa; E, MP-Pb 3573a, folha apresentando ápice levemente redondo, com suaves ondulações nas margens e venação central frouxa; F, MP-Pb 3460a, b, limbo oblanceolado, feixes centrais nítidos e porção basal alongada gradativamente estreita. Scale bars $=1 \mathrm{~cm}$.

Figure 7. Gangamopteris obovata var. major (Feistmantel) Dolianiti: A, MP-Pb 3704, oblanceolate-spatulata leaf, with salient mid-vein bundles, at basal region, evanescent towards apex. G. obovata (Carr.) White: B, MP-Pb 3647, oblanceolate leaf, with obtuse apex and narrow tapering base, mid-vein bundles not prominent, and lateral veins curving stronger at the median and apical leaf regions; $\mathbf{C}, \mathrm{MP}-\mathrm{Pb}$ 2581, oblanceolate-shaped leaf with undulate distal margins, salient mid-vein bundles at median leaf region; $\mathbf{D}$, MP-Pb 2278, oblanceolateshaped leaf with undulate distal margins and mid-vein bundles not prominent; E, MP-Pb 3573a, leaf with rounded apex and undulate distal margins, mid-vein bundles not prominent; F, MP-Pb 3460a, b oblanceolate-shaped leaves showing salient mid-vein bundles and narrow tapering base. Scale bars $=1 \mathrm{~cm}$.

Em nível específico, os espécimes estudados se comparam a Gangamopteris cyclopteroides Feistmantel (Feistmantel, 1879; Surange \& Lele, 1955; Maithy, 1965b) por apresentarem ápice obtuso a levemente redondo, e região mediana ocupada por veias subparalelas que se iniciam na porção basal e seguem até o ápice da folha, onde se encontram mais difusas. Contudo, diferem desta espécie, principalmente, por apresentarem limbo oblanceolado e margens levemente onduladas na região apical. O formato dos espécimes estudados lembra ainda os de $G$. obovata (Carr.) White (White, 1908; Millan, 1989, est. I, fig. 3), G. clarkeana Feistmantel, G. intermedia Maithy e G. obliqua McCoy (conforme Maithy, 1965b). No entanto, os espécimes analisados assemelham-se mais diretamente a G. obovata por: a) seu formato oblanceolado; b) apresentarem ápice redondo a obtuso e limbo estreitando-se gradualmente em direção à região basal; c) possuírem veias laterais que se bifurcam várias vezes e curvam-se suavemente para os bordos, na porção basal da folha, e mais acentuadamente, nas porções mediana e apical da mesma; d) pela maior freqüência de anastomoses junto aos bordos da folha, onde as nervuras encontram-se mais próximas, feição esta que os diferencia das demais espécies próximas. Tendo em vista que tais características são diagnósticas para a espécie G. obovata, justifica-se, portanto, a inclusão do presente material neste táxon. 
Gangamopteris o. var. major (Feistmantel) Dolianiti 1954

(Figuras 7A, 8)

Gangamopteris obovata (auct. non) Maithy 1965b. Iannuzzi \& Souza, 2005:148, fig.4a.

Material descrito. Afloramento Morro do Papaléo: $\mathrm{MP}-\mathrm{Pb}$ 3479, 3703, 3704, 3714, 3724, 4406abA, 4406aB, 4407ab.

Ocorrência. Níveis fossilíferos $7(=\mathrm{N} 7)$ e $8(=\mathrm{N} 8)$ na Formação Rio Bonito, conforme Iannuzzi et al. (2003a, b).

Idade. Permiano (Artinskiano precoce).

Descrição. Os espécimes estudados representam folhas simples, de margens inteiras, simétricas, mesófilas, uma praticamente inteira (MP-Pb 3704), outra com a região mediana e apical (MP-Pb 4406aB) e as demais somente com a região mediana preservada. A forma do limbo é oblanceolada a oblanceolada-espatulada (MP-Pb 3704); com ápice parcialmente preservado (MP-Pb 3704, 4406aB), variando de obtuso a agudo-arredondado; a região basal vai estreitandose gradualmente a partir da porção mediana do limbo; o comprimento das folhas varia de mais de $13 \mathrm{~cm}$ (MP-Pb 4406abA) a maior que 25,5 cm (MP-Pb 3704), enquanto a largura foliar apresenta-se com valores superiores a $4 \mathrm{~cm}$ (MP-Pb 4406abA) e 8,8 cm (MP-Pb 3704). A região mediana é ocupada por veias centrais subparalelas que se encontram mais próximas e acentuadas na porção basal, onde se assemelham a uma venação mediana, e seguem, esvanecendose, anastomosando-se e afilando gradativamente em direção a parte superior da folha, onde as anastomoses tornam-se raras. As veias laterais são sempre bem arqueadas, curvandose em ângulos que variam de $22^{\circ}$ (MP-Pb 3704) a $38^{\circ}(\mathrm{MP}-\mathrm{Pb}$ 3704) e bifurcando e anastomosando-se, através de conexões obliquas, transversais e em "X", o que forma retículos alongados e retangulares; apresentam uma elevada densidade de venação próxima às margens foliares (Figura 8).

Discussão. Os espécimes analisados apresentam anastomoses entre as veias, formando malhas, e ausência de uma nítida venação mediana e, por tais características, classificados no gênero Gangamopteris.

Quanto à forma do limbo os espécimes estudados assemelham-se a Gangamopteris major Feistmantel (Feistmantel, 1879; Maithy, 1965b), G. obovata var. major (Feistmantel) Dolianiti (Dolianiti, 1954b) e G. spathulata McCoy (in Maithy, 1966; Rigby \& Chandra, 1990). Diferem, no entanto, de G. major por apresentar veias laterais arqueadas, formando ângulos de $22^{\circ}$ a $38^{\circ}$, e por suas dimensões maiores. Distinguem-se também de $G$. spathulata pela região mediana ocupada por veias centrais subparalelas que se encontram mais próximas e acentuadas na porção basal, e se esvaecem gradativamente em direção a parte superior da folha. Entretanto, demonstra
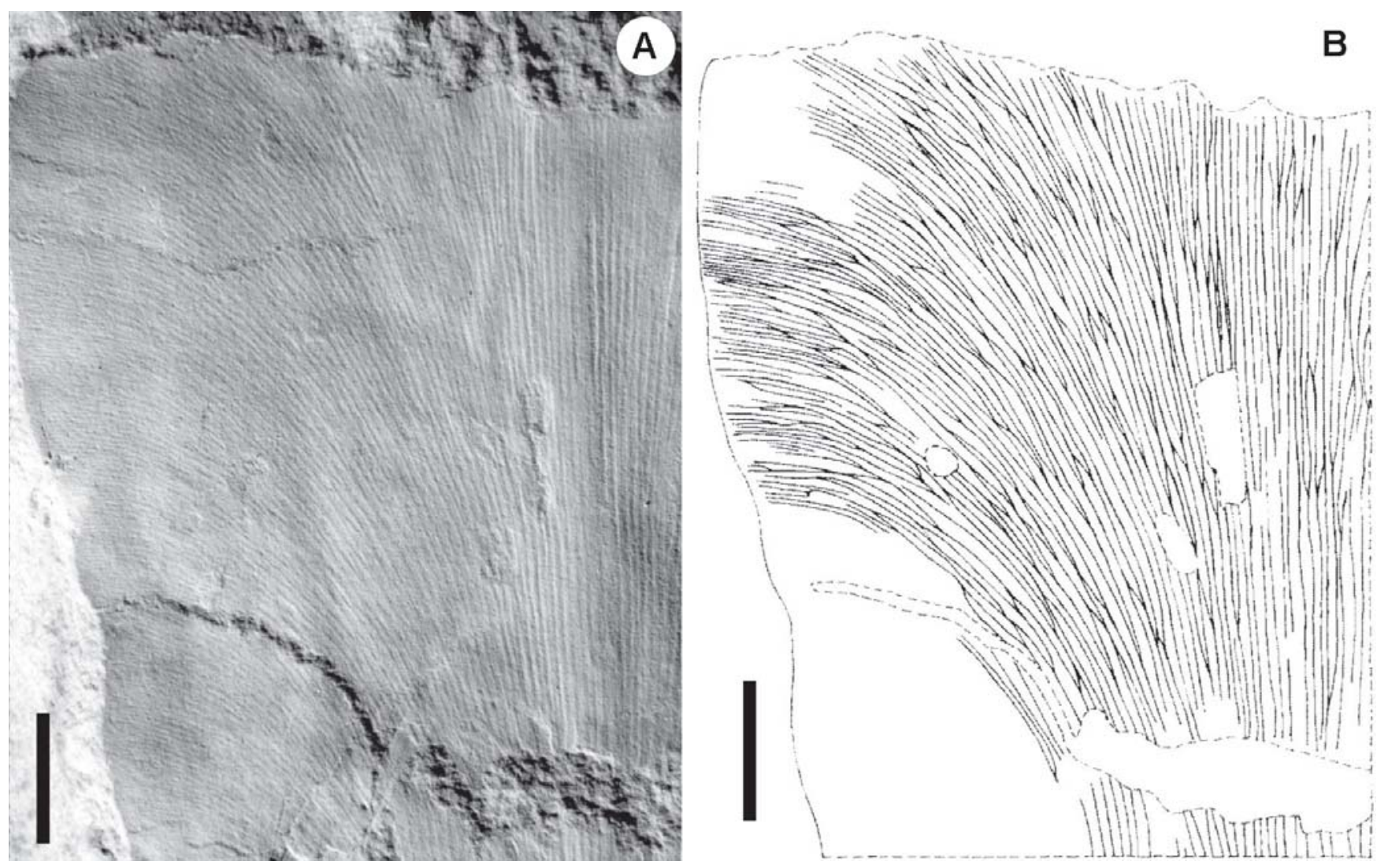

Figura 8. Gangamopteris obovata var. major (Feistmantel) Dolianiti, MP-Pb 3704: foto (A) e desenho (B) mostrando o padrão da venação. Escalas $=1 \mathrm{~cm}$.

Figure 8. Gangamopteris obovata var. major (Feistmantel) Dolianiti, MP-Pb 3704: photo (A) and drawing (B) showing the venation pattern. Scale bars $=1 \mathrm{~cm}$. 
estreita semelhança com G. obovata var. major devido as suas dimensões, veias laterais arqueadas e região mediana ocupada por veias centrais subparalelas, que se encontram mais próximas e acentuadas na porção basal, e difusas e finas em direção a parte superior da folha. Sendo assim, os espécimes estudados correspondem a $G$. obovata var. major, com a qual guardam efetivamente uma identidade em nível específico.

\section{CONCLUSÕES}

A reavaliação taxonômica dos espécimes anteriormente classificados em Rubidgea, provenientes de diversos afloramentos do Permiano Inferior da Bacia do Paraná no Estado do Rio Grande do Sul, concluiu que eles não correspondem à diagnose original do gênero, por apresentarem anastomoses ao longo da lâmina foliar, dispondo-se melhor em Gangamopteris. Assim, considerase que o gênero Rubidgea está ausente dos depósitos permianos do Rio Grande do Sul.

A partir destas observações a presença de formas do morfogênero Rubidgea na Bacia do Paraná fica restrita ao registro feito por Millan \& Dolianiti (1982) para os depósitos do topo do Grupo Itararé, em Cerquilho, São Paulo, de idade eopermiana precoce (Sakmariano?).

A presença de Rubidgea no Gondwana é igualmente rara, tendo sido noticiada apenas para o Permiano Inferior na Índia por Maithy (1965a). Existem alguns autores, inclusive, que não crêem na validade deste morfogênero (Arber, 1905; Seward, 1907; Kovács-Endrödy, 1977) creditando sua determinação a interpretações errôneas por parte daqueles que erigiram ou assinalaram sua ocorrência (i.e. Tate, 1867; Maithy, 1965a).

Pelo exposto, sugere-se uma reavaliação do material descrito por Millan \& Dolianiti (1982). Isto poderá contribuir, de forma mais decisiva, para confirmar ou não Rubidgea como um morfotipo válido entre as folhas de glossopterídeas presentes no Gondwana.

Além da inclusão de todos os fósseis sul-riograndenses anteriormente classificados como Rubidgea em Gangamopteris, é aqui proposta uma separação dos espécimes deste último gênero em quatro morfoespécies, distribuídas em distintos níveis estratigráficos e localidades eopermianas do Rio Grande do Sul, uma delas inédita. Gangamopteris revoluta nov. sp. está presente nos afloramentos Morro do Papaléo (níveis fossilíferos 4 e 8), Acampamento Velho e Cambaí Grande, que expõem níveis correspondentes ao topo do Grupo Itararé até a porção médiosuperior da Formação Rio Bonito, sugerindo um intervalo de que vai do Sakmariano tardio ao Artinskiano precoce para a ocorrência da nova espécie.

Registra-se também, pela primeira vez para o Rio Grande do Sul, a presença de Gangamopteris obovata var. major (Feistmantel) Dolianiti, para a porção médio-superior da Formação Rio Bonito, na seção do Afloramento Morro do Papaléo (níveis fossilíferos 7 e 8). Esta espécie foi originalmente erigida para os depósitos do Membro
Siderópolis, da Formação Rio Bonito, em Criciúma, Santa Catarina (Millan \& Dolianiti, 1982), aos quais se restringia até então sua ocorrência. Este é o primeiro registro da presença de G. obovata var. major para uma localidade fora de sua área tipo, estendendo sua distribuição geográfica em direção ao sul da bacia, o que contribui para confirmar a validade desta espécie. Portanto, apóia-se uma idade artinskiana precoce para o registro de G. obovata var. major no Rio Grande do Sul.

Por fim, duas espécies de Gangamopteris já conhecidas anteriormente para o Permiano são assinaladas. Gangamopteris buriadica Feistmantel tem sua distribuição estratigráfica ampliada, antes restrita ao topo do Grupo Itararé, para a porção médio-superior da Formação Rio Bonito, devido a sua ocorrência, reportada aqui pela primeira vez, no topo do Afloramento de Quitéria. Gangamopteris obovata (Carr.) White, uma das espécies mais comumente assinalada para o gênero, é reconhecida como o único epíteto válido para vários espécimes anteriormente classificados em Rubidgea noticiados de forma preliminar para o topo do Grupo Itararé no Rio Grande do Sul. Além disso, G. obovata tem sua amplitude estratigráfica estendida no estado até a porção médio-superior da Formação Rio Bonito, dada sua presença no topo do Afloramento Morro do Papaléo (nível fossilífero 8). Este fato por si só gera controvérsia, seja do ponto de vista botânico, com vistas à obtenção de uma classificação natural dos táxons fósseis, seja do ponto de vista de identificação taxonômica das folhas fósseis, dadas as distorções preservacionais impostas pelos processos tafonômicos, já observadas por outros autores. Por outro lado, uma saída lógica para este problema é considerar todos os morfotipos foliares como pertencentes a um único morfogênero, no caso Glossopteris, diferenciando-os apenas em nível específico, como já foi sugerido por alguns autores (veja Kovács-Endrödy, 1977).

A não concordância com esta visão fez com que aqui fosse adotada a clássica distinção dos morfotipos de folhas glossopterídeas em nível genérico, considerando como gêneros válidos os táxons Gangamopteris e Glossopteris, e recomendando cuidado na determinação dos gêneros de folhas de glossopterídeas dada a existência de distorções preservacionais que podem mascarar feições diagnósticas, tais como, presença ou não de anastomoses.

\section{AGRADECIMENTOS}

Os autores agradecem ao Conselho Nacional de Desenvolvimento Científico e Tecnológico (CNPq) pelo apoio financeiro (130053/2005-8, PQ309322/2007-3), fundamental para a realização deste trabalho; à D. R. Boardman (PPGeoUFRGS) pelas ilustrações; e a L. F. Lopes (UFRGS) pela produção do material fotográfico. Este trabalho é uma contribuição do Centro de Investigação do Gondwana aos projetos IGCP-471, CNPq (474153/2004-5, 483463/2007-8) e FAPERGS (PROAPP-04/1066.0). Os autores agradecem às sugestões dos revisores que muito contribuiram para o aprimoramento do trabalho. 


\section{REFERÊNCIAS}

Arber, E.A.N. 1902. The Clarke collection of fossil plants from New South Wales. Quarterly Journal of the Geological Society South Afrika, 58:1-26.

Arber, E.A.N. 1905. Catalogue of the Fossil Plants of the Glossopteris Flora. Department of Geology, British Museum, London, $295 \mathrm{p}$.

Archangelsky, S. 1957. Las glossopterideas del Bajo de la Leona. Revista de la Asociacion Geologica Argentina, 12(3):135-166.

Ash, A.; Ellis, B.; Hickey, L.J.; Johnson, K.; Wilf, P. \& Wing, S. 1999. Manual of leaf architecture: morphological description and categorization of dicotyledonous and net-veined monocotyledonous angiosperms. Washington, Leaf Architecture Working Group of Smithsonian Institution, 65 p. <http:// www.peabody.yale.edu/collections/pb/MLA.pdf>

Cazzulo-Klepizig, M.; Guerra-Sommer, M. \& Bossi, E.G. 1980. Revisão fitoestratigráfica do grupo Itararé no Rio Grande do Sul. I. Acampamento Velho, Cambaí Grande, Budó e Morro do Papaléo. Boletim do Instituto de Geociências, 11:55-75.

Chandra, S. \& Surange, K.R. 1979. Revision of the Indian species of Glossopteris. Lucknow, Birbal Sahni Institute of Palaeobotany, $301 \mathrm{p}$.

Dolianiti, E. 1954a. Gangamopteris angustifolia e Gangamopteris buriadica na Formação Maricá do Rio Grande do Sul. Notas Preliminares e Estudos 87:1-6.

Dolianiti, E. 1954b. A flora do Gondwana Inferior em Santa Catarina $V$ - gênero Gangamopteris. Rio de Janeiro, Departamento Nacional da Produção Mineral, Divisão de Geologia e Mineração, p. 1-12 (Notas Preliminares e Estudos 89).

Feistmantel, O. 1879. Fossil Flora of the Gondwana System. I.(suppl.) - The flora of the Talchir-Karharbari beds. Memoirs of the Geological Survey of India, Palaeontologia Indica series 12, 3:1-64.

Guerra-Sommer, M. \& Cazzulo-Klepzig, M. 1981. A tafoflora do Grupo Itararé no Rio Grande do Sul: sua importância bioestratigrafica no Gondwana Sul-Brasileiro: In: CONGRESSO LATINO-AMERICANO PALEONTOLOGIA, 2, 1981. Anais, Porto Alegre, UFRGS, p. 127-140.

Guerra-Sommer, M. \& Cazzulo-Klepzig, M. 1993. Biostratigraphy of the Southern Brazilian Neopalaeozoic Gondwana Sequence: a preliminary palaeobotanical approach. In: INTERNATIONAL CONGRÈS DE LA STRATIGRAPHIE ET GÉOLOGIE DU CARBONIFÈRE ET PERMIEN, 12, 1991. Comptes rendus, Buenos Aires, 2:61-72.

Guerra-Sommer, M. \& Cazzulo-Klepzig, M. 2000a. Early Permian palaeofloras from Southern Brazilian Gondwana: a palaeoclimatic approach. Revista Brasileira de Geociências, 30(3): 486-490.

Guerra-Sommer, M. \& Cazzulo-Klepzig, M. 2000b. As floras Gonduânicas do Paleozóico Superior do Rio Grande do Sul. In: Holz, M. \& De Ros, L. F. (eds.) Paleontologia do Rio Grande do Sul, Centro de Investigações do Gondwana, Universidade Federal do Rio Grande do Sul, p. 67-84.

Guerra-Sommer, M. \& Klippel, L.R. 1985. O gênero Glossopteris no Grupo Itararé do Rio Grande do Sul. Brasília, Ministério das Minas e Energia, Departamento Nacional da Produção Mineral, p. 605-612 (Série Geologia 27).

Guerra-Sommer, M.; Cazzulo-Klepzig, M. \& Marques-Toigo, M. 1980. Revisão fitoestratigráfica do Grupo Itararé no Rio Grande do Sul. III - Área de Faxinal, município de Guaíba, Rio Grande do Sul. Boletim do Instituto de Geociências, 11:76-85.
Iannuzzi, R. \& Souza, P.A. 2005. Floral succession in the Lower Permian deposits of the Brazilian Paraná Basin: an up-to-date overview. New Mexico Museum of Natural History \& Science Bulletin, 30:144-149.

Iannuzzi, R.; Marques-Toigo, M.; Scherer, C.M.S.; Caravaca, G.; Vieira, C.E.L. \& Pereira, L.S. 2003a. Reavaliação da fitobioestratigrafia da seqüência gondwânica sul-riograndense: estudo de caso do afloramento Morro do Papaléo (Bacia do Paraná, Permiano Inferior). In: ENCONTRO SOBRE ESTRATIGRAFIA DO RIO GRANDE DO SUL: ESCUDOS E BACIAS, 1, 2003. Anais, Porto Alegre, UFRGS, p. 182-185.

Iannuzzi, R.; Marques-Toigo, M.; Scherer, C.M.S.; Caravaca, G., Vieira, C.E.L. \& Pereira, L.S. 2003b. Phytobiostratigraphical revaluation of the southern Brazilian Gondwana sequence (Paraná Basin, Lower Permian): In: INTERNATIONAL CONGRESS ON CARBONIFEROUS AND PERMIAN STRATIGRAPHY, 15, 2003. Abstracts, Utrecht, p. 240-242.

Iannuzzi, R.; Scherer, C.M.S.; Souza, P.A., Holz, M.; Caravaca, G.; Adami-Rodrigues, K; Tybusch, G.P.; Souza, J.M.; Smaniotto, L.P.; Fischer, T.V.; Silveira, A.S.; Lykawka, R.; Boardman, D.R. \& Barboza, E.G. 2006. Afloramento Morro do Papaléo, Mariana Pimentel, RS. Registro ímpar da sucessão pós-glacial do Paleozóico da Bacia do Paraná. In: C. Schobbenhaus et al. (eds.) Sítios Geológicos e Paleontológicos do Brasil. vol. 2. <http://www.unb.br/ig/sigep/sitio101/ sitio101.pdf>

Jasper, A. 2004. O modelo deposicional do afloramento Quitéria e a evolução dos biomas úmidos no Permiano Inferior do sul da Bacia do Paraná. Programa de Pós-graduação em Geociências, Universidade Federal do Rio Grande do Sul, Tese de Doutorado, $248 \mathrm{p}$.

Jasper, A.; Menegat, R.; Guerra-Sommer, M.; Cazzulo-Klepzig, M. \& Souza, P.A. 2006. Depositional cyclicity and paleoecological variability in an outcrop of Rio Bonito formation, Early Permian, Paraná Basin, Rio Grande do Sul, Brazil. Journal of South American Earth Sciences, 21:276-293.

Kovács-Endrödy, E. 1977. The taxonomic status of the genus Rubidgea. Bothalia, 2(12):313-317.

Maithy, P.K. 1965a. Studies in the Glossopteris flora of India - 17. On the genus Rubidgea Tate. The Palaeobotanist, 13(1):42-43.

Maithy, P.K. 1965b. Studies in the Glossopteris flora of India - 26. Glossopteridales from the Karharbari beds, Giridih coalfield, India. The Palaeobotanist, 13(1):248-263.

Maithy, P.K. 1966. Studies in the Glossopteris flora of India - 32. On the genus Gangamopteris McCoy. The Palaeobotanist, 14(1-3):46-51.

Maithy, P.K. 1998. Morphotaxonomic re-evaluation of Gangamopteris(?) buriadica Feistmantel. Journal of the Palaeontological Society of India, 43:85-88.

McCoy, F. 1847. On the fossil botany and zoology of the rocks associated with the coal of Australia. The Annals and Magazine of Natural History, 20(132):145-157.

Millan, J.H. \& Dolianiti, E. 1982. Sobre a presença do gênero Rubidgea no Eogondwana de Cerquilho, Subgrupo Itararé de São Paulo. Boletim do Instituto de Geociências, 13:43-134.

Millan, J.H. 1989. Sobre a presença de formas foliares mais primitivas de glossopterídeas (gênero Gangamopteris no Município de Cerquilho, carvão do Eogondwana do Estado de São Paulo). Anais da Academia Brasileira de Ciências, 61(2):201213.

Plumstead, E. P. 1962. Fossil floras of Antartica. Trans-Antartic Expedition, Scientific Reports, 9:7-153. 
Piccoli, A.E.M.; Menegat, R.; Guerra-Sommer, M.; Marques-Toigo, M.E. \& Porcher, C.C. 1991. Faciologia da seqüência sedimentar nas folhas de Quitéria e Várzea do Capivarita, Rio Grande do Sul. Pesquisas, 18(1):31-43.

Ricardi-Branco, F. \& Bernardes de Oliveira, M.E.C. 2000. Gangamopteris roesleri sp. nov., da tafoflora Eopermiana de Cerquilho (SP), Grupo Tubarão, Bacia do Paraná, Brasil. Revista Universidade Guarulhos, Geociências, 5 (n. esp.):44-48.

Rigby, J.F. \& Chandra, S. 1990. Revision of the Permian Gondwana flora from Bacchus Marsh, Victoria: In: IOP CONFERENCE, 3, 1990. Proceedings, Melbourne, p. 107-113.

Rohn, R. \& Babinski, M.E.C.B. \& Rösler, O. 1984. Glossopteris da Formação Rio do Rasto no sul do estado do Paraná: In: CONGRESSO BRASILEIRO DE GEOLOGIA, 33, 1984. Anais, Rio de Janeiro, p. 1047-1061.

Rohn, R.; Longhim, M.E.; Bernardes-de-Oliveira, M.E. \& Navarro, G.R.B. 2000. Nova ocorrência fitofossilífera NeocarboníferaEopermiana do Subgrupo Itararé, à margem esquerda do Rio Capivari, município de Tietê, SP, Brasil. Revista Universidade Guarulhos, Geociências, 5(n. esp.):57-61.

Seward, A.C. 1907. Permo-Carboniferous plants from Kashmir. Record Geological Survey of India, 36:481-487.

Seward, A.C. 1908. Fossil Flora of Cape Colony. Annals South Afrika Museum, 4:83-90.

Seward, A.C. 1910. Fossil Plants. Cambridge, Cambridge University
Press, v. 2, 608 p.

Srivastava, A.K. 1991. Evolutionary tendency in the venation pattern of Glossopteridales. Geobios, 4(24):383-386.

Stewart, W.N. \& Rothwell, G.W. 1993. Paleobotany and the evolution of plants. Cambridge, Cambridge University Press. $521 \mathrm{p}$.

Surange, K.R. \& Lele, K.M. 1955. Studies in the Glossopteris flora of India - 3. Plant fossils from the Talchir Needle Shales from Giridih coalfield. The Palaeobotanist, 4:153-157.

Surange, K.R. \& Srivastava, P.N. 1956. Studies in the Glossopteris flora of India - 5. Generic status of Glossopteris, Gangamopteris and Palaeovittaria. The Palaeobotanist, 5(1):46-49.

Tate, R. 1867. On some secondary fossils from South Afrika. The Quarterly Journal of the Geological Society of London, 23:139174.

Vieira, C.E.L. \& Iannuzzi, R. 2000. Presença de Pecopteris e Asterotheca no Afloramento Morro do Papaléo, município de Mariana Pimentel, RS (Formação Rio Bonito, Eopermiano da Bacia do Paraná). Pesquisas, 27(2):49-64.

Walkom, A.B. 1922. Paleozoic floras of Queensland. Part I. The flora of the Lower and Upper Bowen series. Queensland Geological Survey, 270:1-64.

White, D. 1908. Fossil Flora of the Coal Measures of Brazil. In: I.C. White (ed.) Comissão de Estudos das Minas de Carvão de Pedra do Brasil, Relatório

Received in May, 2008; accepted in July, 2008. 